\title{
AC 2007-68: THE USE OF LABVIEW AND DATA ACQUISITION UNIT TO MONITOR AND CONTROL AIR-CONDITIONING PROCESSES
}

Hosni Abu-Mulaweh, Indiana University-Purdue University-Fort Wayne 


\title{
The Use of LabVIEW and Data Acquisition Unit to Monitor and Control Air-Conditioning Processes
}

\author{
Hosni I. Abu-Mulaweh \\ Department of Engineering \\ Indiana University-Purdue University Fort Wayne \\ Fort Wayne, IN 46805, USA
}

\begin{abstract}
A portable experimental setup for demonstrating air-conditioning processes was designed, developed and constructed by a multidisciplinary capstone senior design team. This experimental apparatus is currently being used to demonstrate to undergraduate students air-conditioning processes such as cooling, heating, and humidification. The level of cooling, heating, or humidification is being monitored and controlled using a PC-based control system which consists of LabVIEW and data acquisition unit. This paper provides details about the integration of the electrical/electronic component and the control system.
\end{abstract}

\section{Introduction}

The assessment results of the mechanical engineering program at Indiana University-Purdue University Fort Wayne have shown that the mechanical engineering curriculum lacks "high tech" equipment and experiments. The students have indicated that they would like to see more use of computer data acquisition systems and the availability of computers in the laboratories so they can perform on-site data analysis and calibration. Currently there is only one mobile data acquisition system that is rarely used in some of the laboratory courses. To address this concern, the engineering faculty at Indiana University-Purdue University Fort Wayne have integrated computer data acquisition in some of the existing and new experiments.

One of the new "high tech" laboratory experimental apparatus that was designed, developed, and constructed is a bench-top air conditioning processes demonstrating unit. This experimental apparatus is currently being used to demonstrate to undergraduate students air-conditioning processes such as cooling, heating, and humidification. The level of cooling, heating, or humidification is being monitored and controlled using a PC-based control system which consists of LabVIEW and data acquisition unit. LabVIEW and computer data acquisition has been widely utilized to update and modernize equipment and laboratory experimental apparatus [1-5]. 


\section{The Design Process}

The design process that the students follow in the capstone senior design project is the one outlined by Bejan et al. [6] and Jaluria [7]. The first essential and basic feature of this process is the formulation of the problem statement. The formulation of the design problem statement involves determining the requirements of the system, the given parameters, the design variables, any limitations or constraints, and any additional considerations arising from safety, financial, environmental, or other concerns.

In order for this experimental apparatus to function as a useful piece of lab equipment, the following requirements and specifications need to be met. These include requirements that will make the apparatus useful for demonstrating air conditioning processes as well as ensure the unit will operate safely.

Portability /Mobility: The apparatus should be portable for optimum use of laboratory space and for operation outdoors if desired. The unit shall not exceed a width of $90 \mathrm{~cm}$ or a height of $150 \mathrm{~cm}$.

System Similarity: The apparatus should have the major elements of a building air conditioning system (e.g. a cooling coil, a fan, a conditioned space where temperature and relative humidity are maintained at desired levels, supply and return ducting, and a method for introducing outside air).

Variable Heat Load: Means for a variable heat load in the conditioned space must be provided to simulate the effect of building occupants, lighting, heat gain through walls and ceiling, etc.

Airflow Control: Motor-driven dampers should be used to control supply airflow and outside air induction.

$\underline{\text { Instrumentation }}$ - The instrumentation requirements have two distinct sets of necessary specifications.

1. The air conditioning unit must be fully instrumented with autonomous gages so that it may demonstrate its principles without needing to be hooked up to an outside computer.

2. Although it may operate without an external computer, the air conditioning unit must also be outfitted with a data acquisition (DAQ) bus that can be connected to an external DAQ board or software system. This bus must be able to supply to the external DAQ system the measurements that will be shown on the onboard instrumentation. In addition, the measurements must be logged by the DAQ.

\section{Experimental Apparatus}

A bench-top air conditioning experimental apparatus, shown in Figure 1, was designed, developed, and constructed for instructional and demonstrative purposes. This air conditioning experimental setup was designed around the vapor compression refrigeration cycle. This

Proceedings of the 2007 American Society for Engineering Education Annual Conference \& Exposition

Copyright $\odot$ 2007, American Society for Engineering Education 
experimental apparatus has an intuitive user interface, reliable, safe for student use, and portable. The interface is capable of allowing data acquisition by an existing laboratory computer. The unit is capable of demonstrating air conditioning processes such as cooling, heating, and humidification. The level of cooling, heating, or humidification is being monitored and controlled using a PC-based control system which consists of LabVIEW and data acquisition unit. Figure 2 along with Table 1 illustrate the different measurements and their location in the air conditioning system. Also the table indicates the sensor readings that are used in controlling the system with LabVIEW.

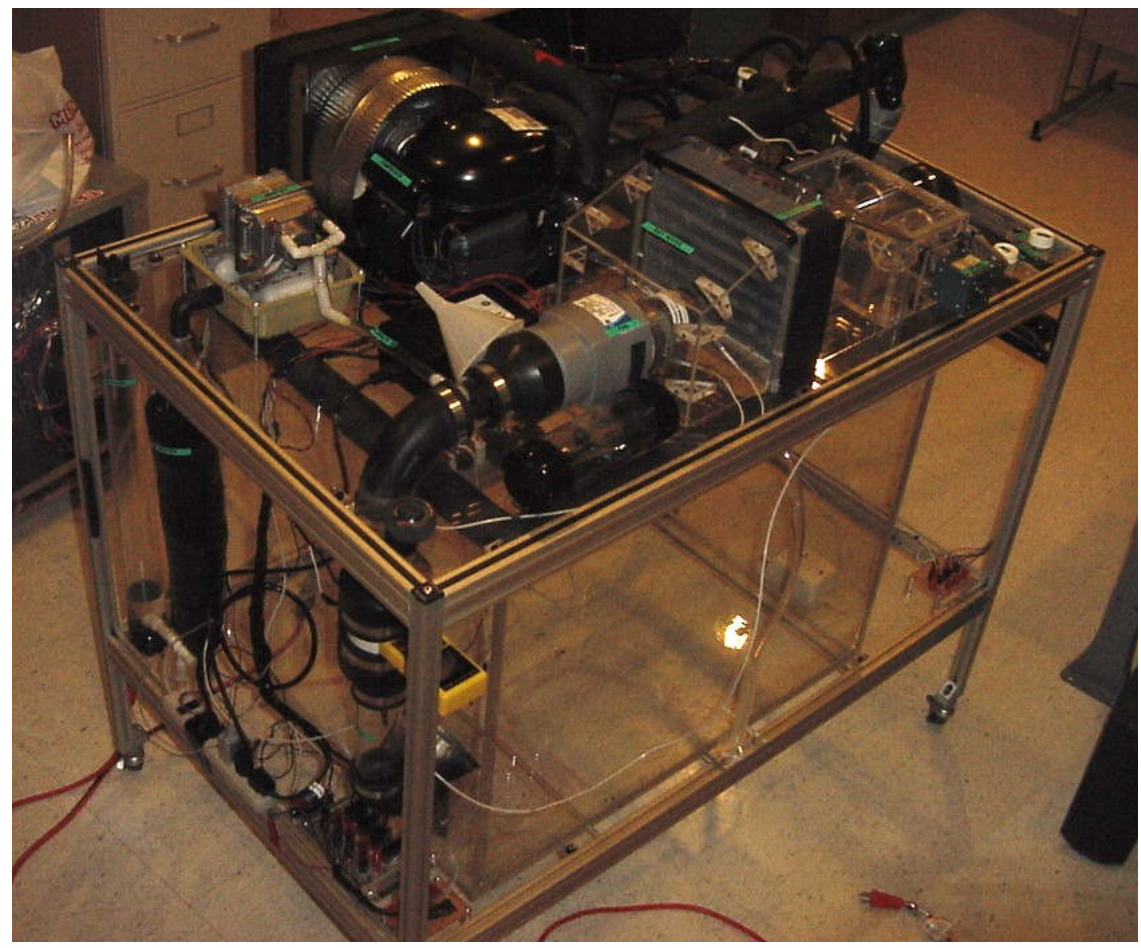

Fig. 1: Air-conditioning experimental apparatus

\section{Integration of the Electrical/Electronic Component}

All of the low voltage electrical components were tested for functionality before assembly into their respective circuits. This was done by applying voltages to each chip and checking output for correctness. After these individual components were tested, each of the circuits were temporarily built on a breadboard and tested to verify that they worked as expected. This was proven by applying inputs of voltages or frequencies from lab equipment and measuring the output voltages with a handheld meter. 


\section{Temperature Measurements}

Temperature sensors can be divided into two main groups which are contact and non-contact sensors. Contact sensors measure their own temperature. It assumes that the object and sensor are in thermal equilibrium. A thermocouple falls into this group of contact sensors.

Thermocouples are based on the principle that when two dissimilar metals are joined, a predictable voltage will be generated that relates to the difference in temperature between the measuring point and the reference point. Thermocouples of J-type are used to measure the temperature in several locations throughout the system (refer to Fig. 2 and Table 1). A temperature display unit is utilized to monitor the temperature readings. Since there are several thermocouples, a switching device is used to control which thermocouple reading is being displayed.

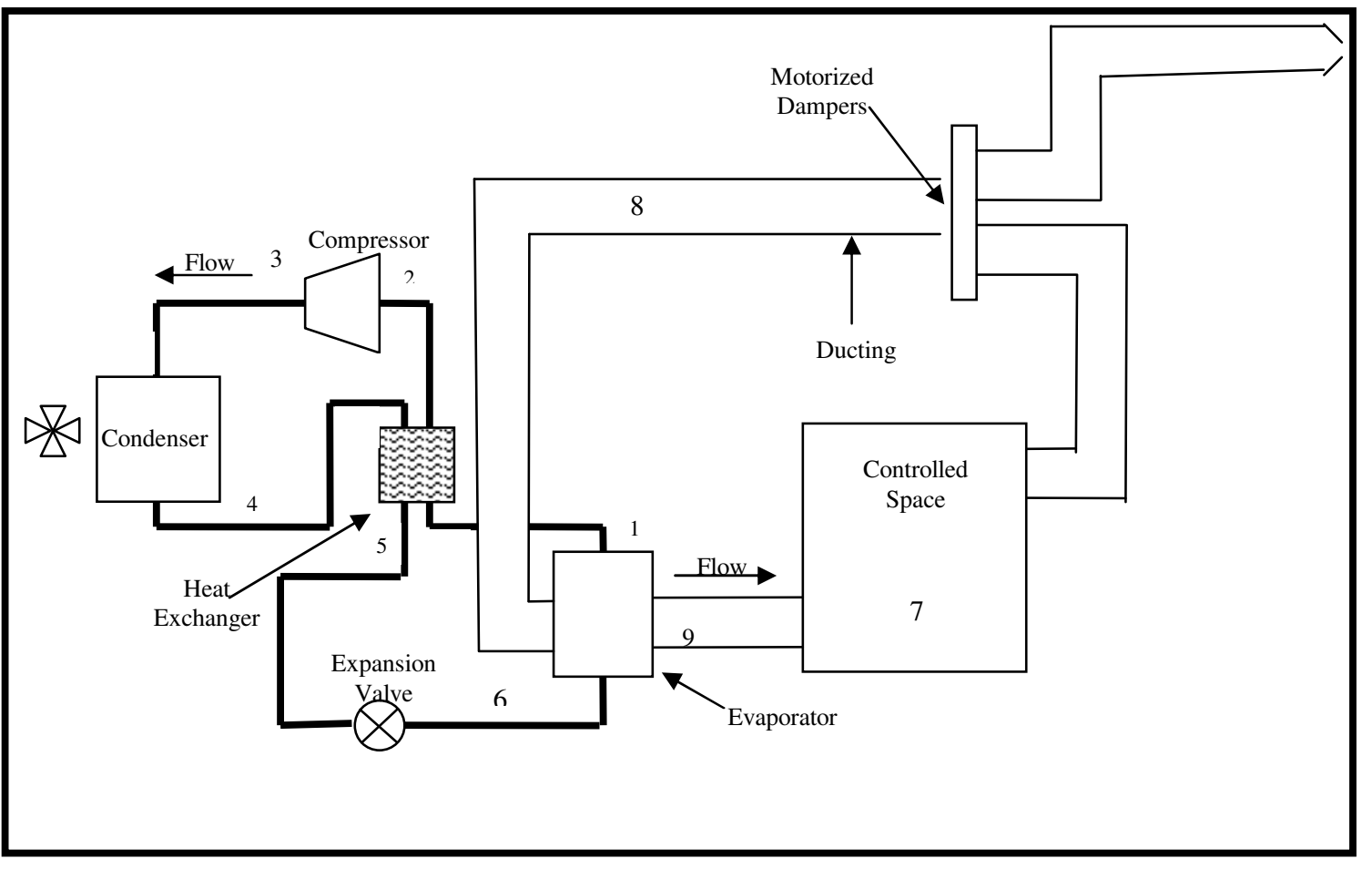

Fig. 2: Measuring sensors locations

\section{$\underline{\text { Pressure Measurements }}$}

The pressure sensing element is a pair of parallel plates which forms a capacitor. As the pressure varies, the diaphragm flexes and the distance between the capacitor plates changes. An integrated circuit in the transducer measures the capacitance and converts it to a voltage linearly proportional to the pressure. The output is ratiometric to supply voltage. This means that, instead of the sensor output voltage itself being the output, it is actually the ratio of the sensor output to the sensor supply voltage which is proportional to pressure.

A pressure display unit is used to monitor the pressure readings. There is only one display box

Proceedings of the 2007 American Society for Engineering Education Annual Conference \& Exposition Copyright $\odot$ 2007, American Society for Engineering Education 
for the pressure settings. Therefore a switching device is used to control which pressure reading is being displayed. The specification sheet for the sensor provided a transfer function based on a $5.00 \mathrm{Vdc}$ supply voltage. The formula is given below:

$$
P(\text { psig })=50.0 \times V_{\text {OUT }}-39.7
$$

Pressure is measured in four different locations of this system (refer to Fig. 2 and Table 1). The sensor chosen is the Texas Instruments 2CP5-49 sensor. It is a ceramic capacitive sensor that has a pressure range from -14.7 to $185 \mathrm{psig}$.

\section{Relative Humidity \& Temperature Measurements}

The relative humidity $(\mathrm{RH})$ and temperature are monitored in two locations of the system (refer to Fig. 2 and Table 1). The sensor chosen is the Honeywell 3610-003. A separate display box is used to view the readings. Since there are two humidity sensors, a switching device is used to control which sensor reading is being displayed.

The RH sensor is a laser trimmed thermoset polymer capacitive sensing element with on-chip integrated signal conditioning. As the relative humidity level changes, so does the capacitive value. This is translated into a change in the voltage output of the sensor.

\section{Air and Refrigerant Flowrates Measurements}

Air and refrigerant flowrates are measured, respectively; at location 8 and location 5 (refer to Fig. 1 and Table). The air flow sensor is the DAM1, which is an integral vane anemometer. This device includes a digital display unit. The refrigerant flow sensor is the Gems FT110 which is a turbine flow rate sensor. A separate display is used to view the resulting data.

\section{Interface and Control System}

Figure 3 illustrates how the data acquisition board is connected to the sensors.

For the data acquisition board, each channel may be programmed with a unique gain of $0.5,1.0$, 10 , or 100 to maximize the 12-bit analog-to-digital converter resolution. The interface between the data acquisition board and LabVIEW is shown in Fig. 4. The data from the analog channels is converted into a digital signal. LabVIEW then reads the data and calculates the temperature and relative humidity. Then in the control system design, a decision has to be made as to what action is performed. The control bus sends the signal to the digital input/output lines. These are sent to the relay box which turns the five components on or off.

The decisions that can be made are summarized in the Table 2. The temperature and humidity within the enclosure must be controlled by operating the vapor compression cycle, stream heating element, and the air pump to the bubbler humidification system according to present sensor conditions. The variation of temperature and humidity yields the nine different controllable cases (Table 2). In terms of processing conditions “+” = above set point, “_" = below set point, "@” = 
at set point. For all controlled elements "1" = ON, "0" = OFF.

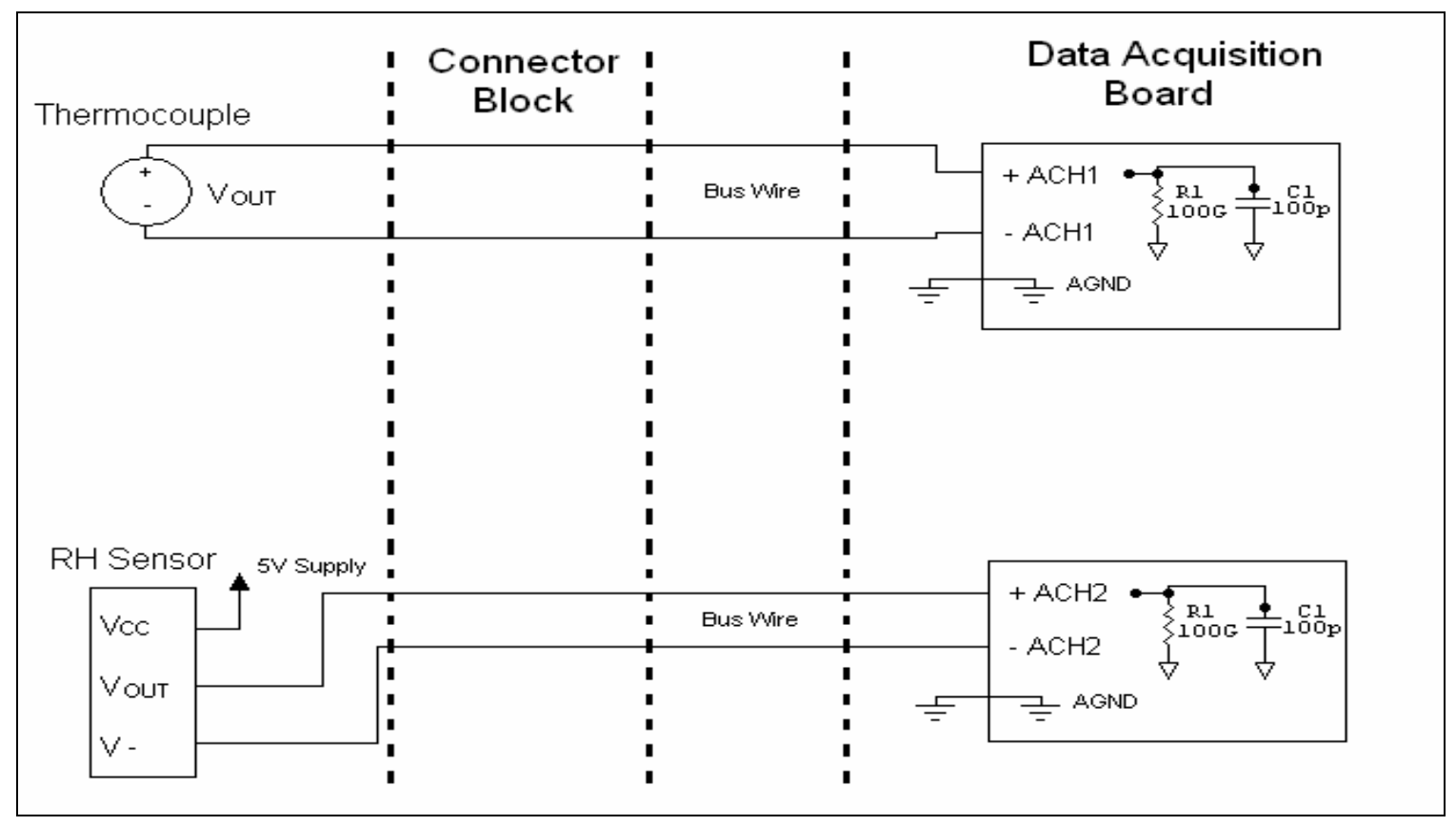

Fig.3: Sensor to DAQ Board Diagram

The controls are similar to a programmable logic control. There are a series of "if statements" which compare the inputs of the system and then make a decision based on the logic of the controls. There are three main parts: 1) the data acquisition of the signals (this process uses the DAQ board to obtain the signals from the sensors and makes the values available to the software of the program),2) the logic which makes the decision of what units need to be on or off based on the inputs that are acquired by the software, and 3) writing the decision of what units should be on or off to the digital output lines. These lines are connected to relays which control the power to the unit.

The controls for this unit used National Instruments LABVIEW 6 software and the 6024 data acquisition board. The screen that the users use most often is the front panel. The front panel is the interactive interface which has the appearance of physical instruments. The front panel used for this unit is shown in Fig. 5.

The source code is a block diagram. The block diagram is an executable program that can be broken into three categories which are acquisition, logic control, and digital output. 


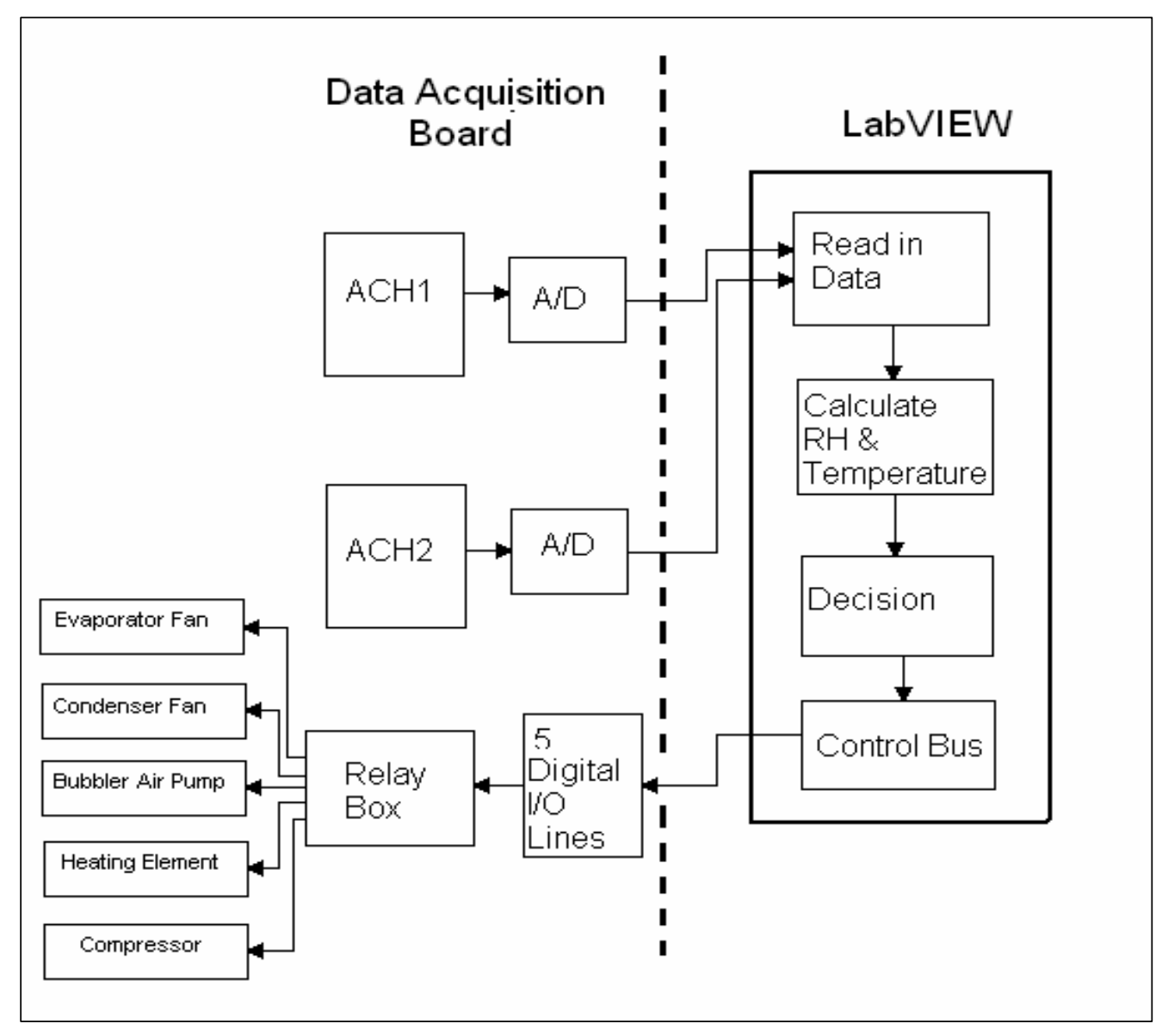

Figure 4: DAQ Board to LabVIEW Interface

\section{Acquisition}

The data acquisition portion of the program for the temperature and relative humidity is shown in Fig. 6. This block diagram is inside a loop, executed at a specified rate. For this program the rate is every 1000 milliseconds. The output of the thermocouple and relative humidity signals are connected to two separate analog channels on the data acquisition (DAQ) board. In the software, the AI Sample Channels VI is used for acquiring the thermocouple and the relative humidity signals. The channels were configured with software for the appropriate gain of the signal. In the case of the thermocouple the gain was set to be 100 which has a range of -50 to 50 millivolts with a precision of 24.41 microvolts. The relative humidity channel was set with gain of 1 and has a range of -5 to 5 volts and a precision of 2.44 millivolts. 


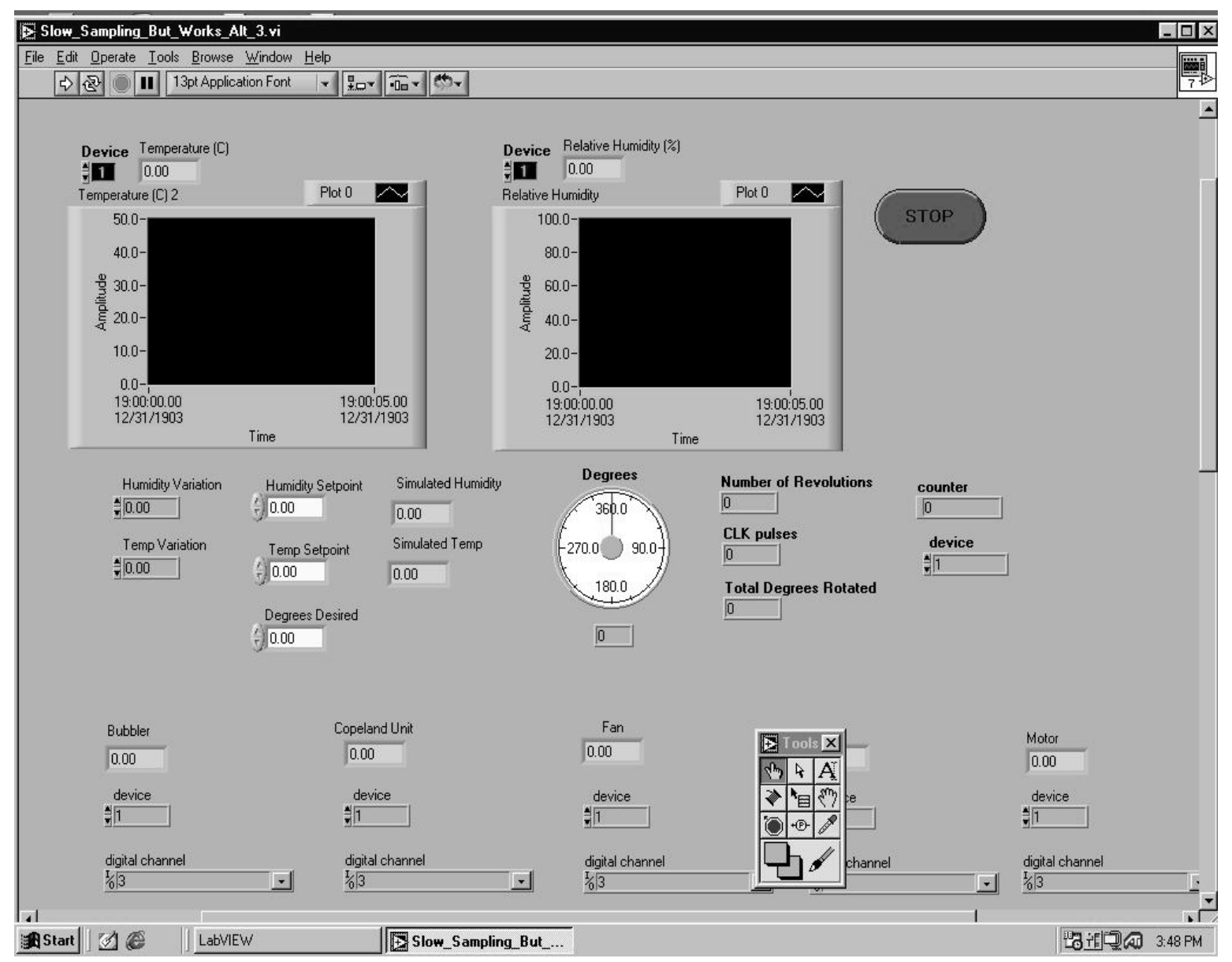

Fig. 5: Front Panel Display

For the thermocouple signal, the values acquired are sent to a waveform graph where they are displayed on the front panel. There is also an indicator digital display to read the numerical value. The statistical mean of these values is then calculated.

For the relative humidity signal, the voltage output of the sensor is acquired. A mathematical operation is then performed to convert the voltage into a percentage for the relative humidity reading. This reading is displayed on a waveform graph on the front panel as well as a digital indicator where the numerical value is read. The statistical mean of these values is calculated.

Figure 7 presents the data acquisition portion of the program that performs the flue encoder acquisition. The encoder generates pulses that are counted by a programmable function input (PFI) pin labeled GPCTR0_SOURCE on the DAQ board. 


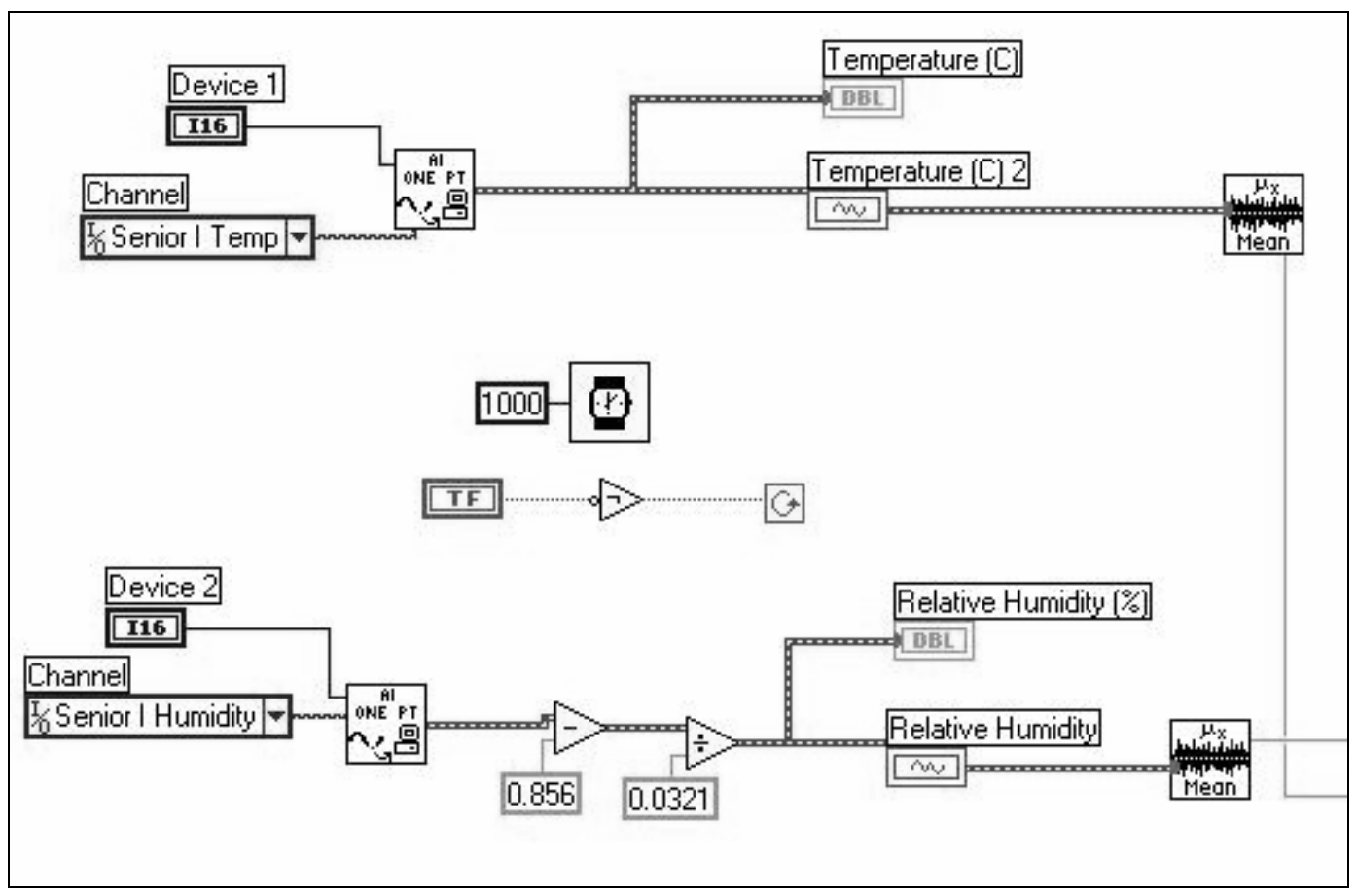

Figure 6: Temperature and Relative Humidity Acquisition

\section{Logic Control}

The logic portion of the program consists of comparing the actual values with the desired setpoints. Figure 8 shows the programming for the comparison decisions of the relative humidity and temperature of the enclosure. The comparison consists of asking the following questions: Actual RH Value $>$ RH Setpoint + RH Variation? if yes, S1 = True; no, S1 = False Actual RH Value < RH Setpoint - RH Variation? if yes, S2 = True; no, S2 = False Actual Temperature $>$ Temperature Setpoint + Temperature Variation? if yes, S3 = True; no, $\mathrm{S} 3=$ False Actual Temperature < Temperature Setpoint - Temperature Variation? if yes, S4 = True; no, $\mathrm{S} 4$ = False

The controls of the temperature and relative humidity settings yields nine different cases as described in the Table 2. The logic control for the bubbler, compressor, evaporator fan, and heater is sown in Fig. 9. The final equations for the four units become:

Bubbler: if $\mathrm{S} 2=$ True, bubbler $=1$ (on)

$$
\text { S2 }=\text { False, bubbler }=0 \text { (off) }
$$

Compressor \& Condenser Fan: if S1 + S3 = True, Copeland Unit = 1 (on)

$$
\mathrm{S} 1+\mathrm{S} 3=\text { False, Copeland Unit }=0 \text { (off) }
$$


Evaporator Fan: if $\mathrm{S} 1+\mathrm{S} 2+\mathrm{S} 3+\mathrm{S} 4=$ True, Fan $=1$ (on)

$\mathrm{S} 1+\mathrm{S} 2+\mathrm{S} 3+\mathrm{S} 4=$ False, Fan $=0$ (off)

Stream Heater: if $[(\mathrm{S} 1+\mathrm{S} 4) * \mathrm{~S} 3=(\mathrm{S} 1+\mathrm{S} 4)]=$ True, Heater $=0($ off $)$

$\left[(\mathrm{S} 1+\mathrm{S} 4)^{*} \mathrm{~S} 3 \neq(\mathrm{S} 1+\mathrm{S} 4)\right]=$ False, Heater $=1$ (on)

The control for the flue motor is presented in Fig. 10. The pulses that were counted by the acquisition are converted into a value of degrees by the program. If the number of degrees turned by the motor is less than the desired number of degrees, the flue motor is turned on. Otherwise, the motor is off.

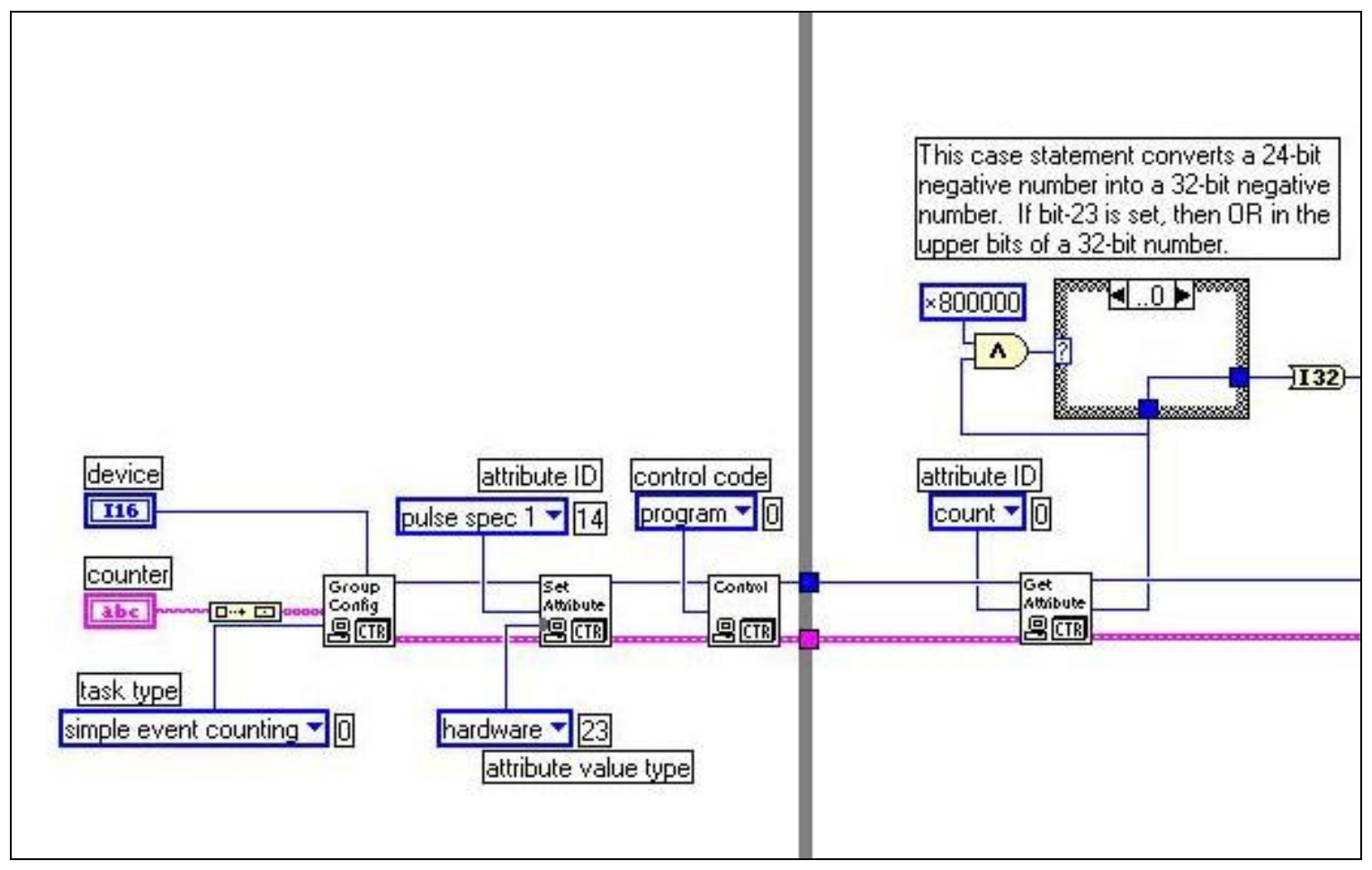

Figure 7: Flue Encoder Acquisition

\section{Digital Output}

The third portion of the software programming is to use the digital lines as outputs to the relays of the system. The "Write to Digital Line" VIs were used to accomplish these tasks. This VI sets a particular line on a port to a logical high (5 volts) or low state ( 0 volts). The green dotted line is the line state command in which True is the high state and False is the low state. 


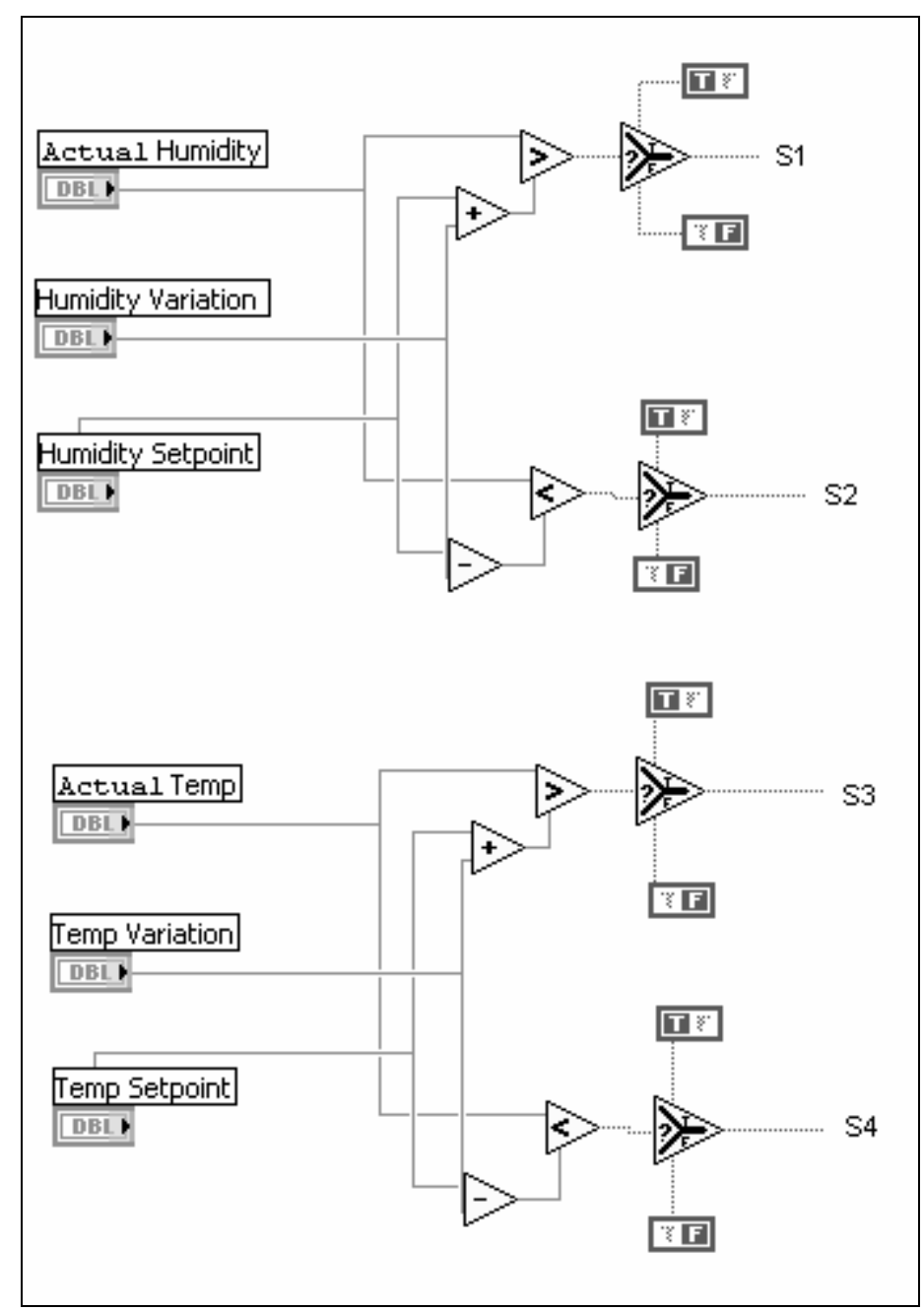

Figure 8: Comparison of Setpoint with Actual Readings

\section{Testing of Control}

The control system was tested to validate the proper functioning of the system. The first test of the unit was to verify that the correct set point conditions matched the digital line outputs listed in Table 1. The state of the digital line was verified by reading the component value on the front panel which was a " 1 " for on and a " 0 " for off. The digital lines were then verified to be working by connecting a volt meter across the individual channels and tested. When the digital line was off, the voltage was 0 . When the digital line was on, the voltage was 5.01 volts. Thus, the component state requirements for the conditions of the table were met. 


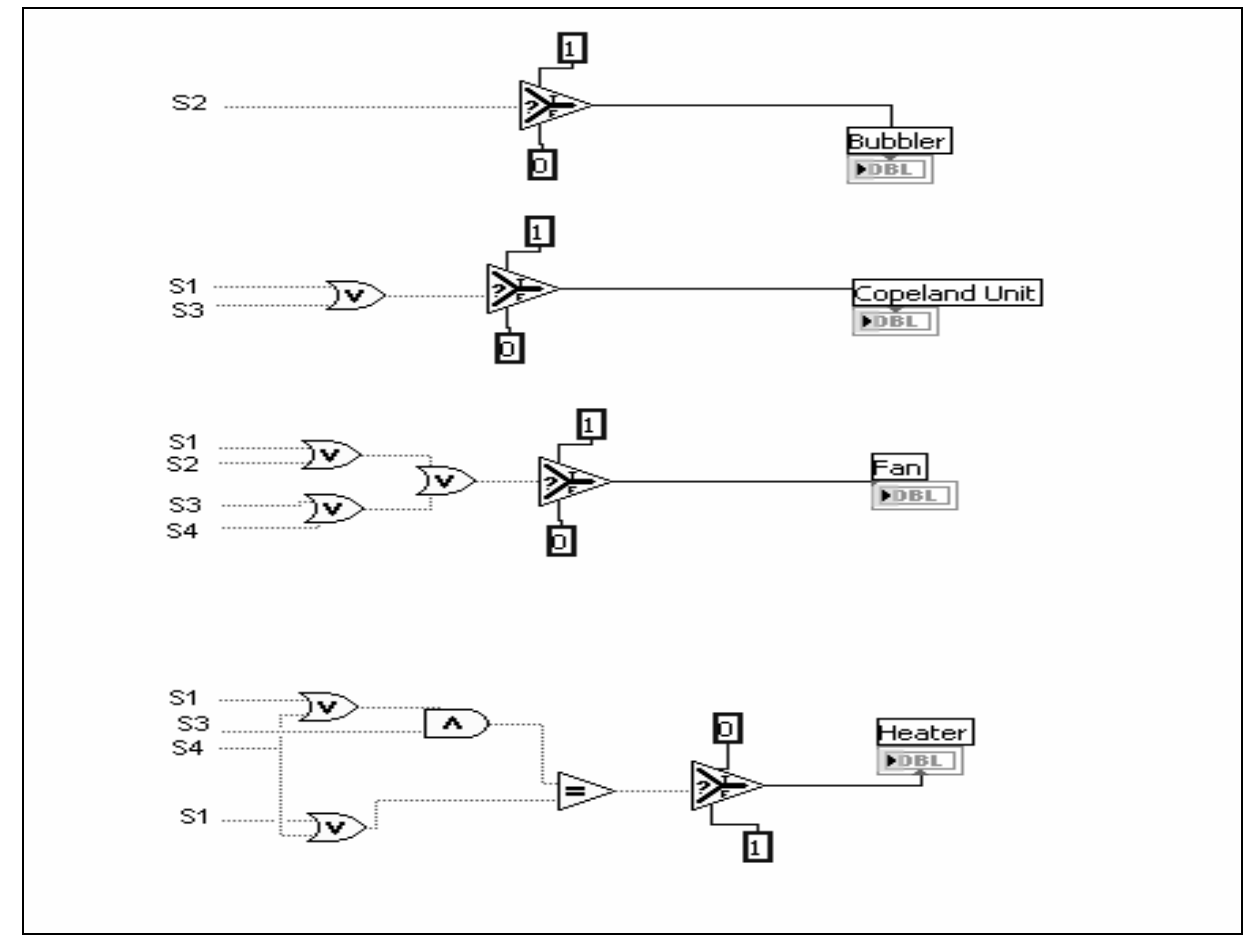

Figure 9: Logic Control for Bubbler, Copeland compressor, Fan, and Heater.

The second part of the testing was to connect the relays of the components to the digital lines and verify that the digital output line, the relays, and the components worked as expected. There was a problem encountered during this initial run of the control system. A difficulty regarding the signal readings for both the thermocouple and relative humidity sensor that was encountered in early phase of the project was that there was a slight fluctuation for each reading which was sampled every one second. The temperature ranged from $\pm 0.9{ }^{\circ} \mathrm{C}$. This created a problem for the control system. When the desired set point was reached by the system, the digital relays would switch on or off the appropriate controlled components. However, when the next sample was collected one second later, this new value was not at the set point. This then caused the components to come back on or off before the set point was reached. Essentially there was a one second cycling as the signal read fluctuated around the set point value.

The on and off switching of the compressor was dangerous to the longevity of the unit and the effectiveness of the controls. To correct this problem, RC circuit, shown in Fig. 11, that produces a time delay to the relays was pursued. This circuit uses an op amp and a npn transistor. The op amp was used for the impedance matching problem. The transistor was used due to the op amps inability to handle the current and controlled the switching of the relay.

The average of the actual time that the relays switched when the digital line went high was found to be 3.9 seconds. The average time for the relays to switch off when the digital line went low was 5.8 seconds. 


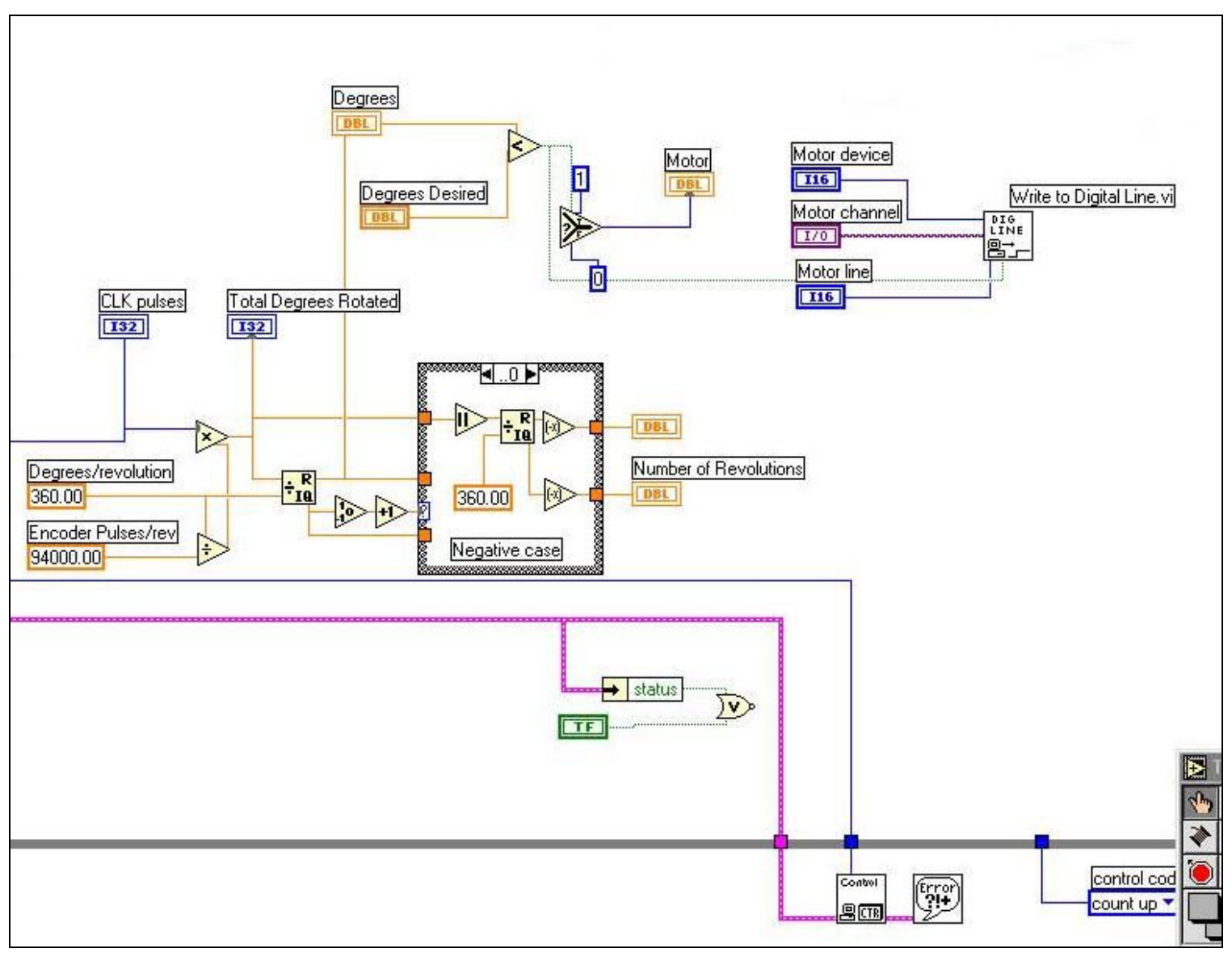

Figure 10: Logic Control for Flue Motor

The RC circuit was used for the components of the bubbler, the condenser and compressor unit, and the fan. The rapid switching of these components could cause damage. For the motor control, a quick response was necessary for the flue to be shut off in the correct position. If a delay was created, the motor would greatly overshoot the desired position.

Three RC circuits, shown in Fig. 11, were constructing and connected to the digital output lines of the DAQ board. The system was tested to verify that the new circuits corrected the rapid switching. It was found that when the signal fluctuated around the set point, the circuit stopped the relay from switching on and off every second. When the system read a reading that was below the set point for 4-5 seconds consistently, then the relay would be switched.

\section{Conclusion}

A portable experimental setup for demonstrating air-conditioning processes was designed, developed and constructed by a multidisciplinary capstone senior design team. This experimental apparatus is currently being used to demonstrate to undergraduate students air-conditioning processes such as cooling, heating, and humidification. The level of cooling, heating, or 
humidification is being monitored and controlled using a PC-based control system which consists of LabVIEW and data acquisition unit. The development of this unit was accomplished with zero cost to the engineering department at Indiana University-Purdue University Fort Wayne. This was made possible for two main reasons: the financial support from ASHRAE and the effort of a capstone senior design team. The experimental apparatus is portable.

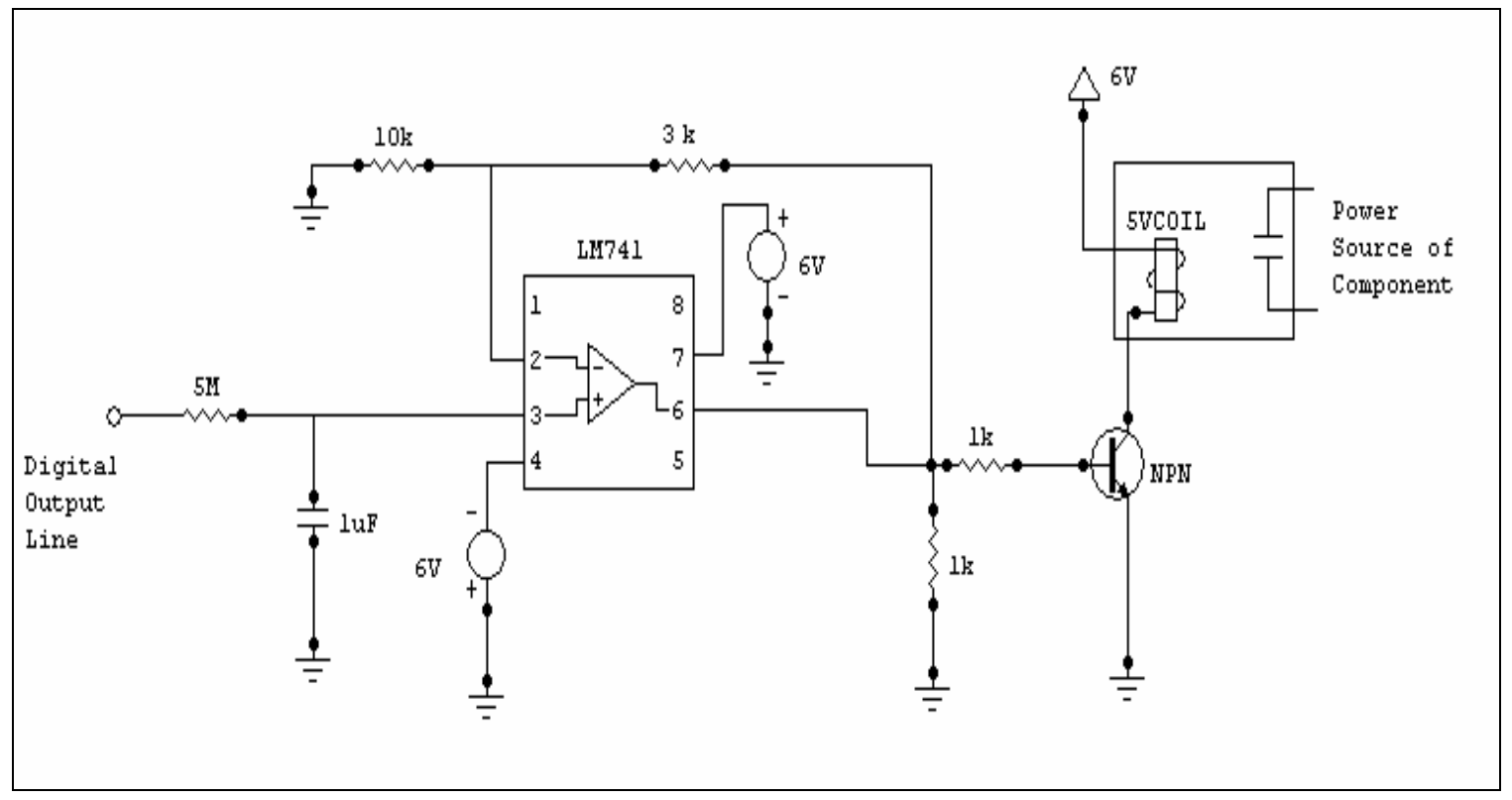

Fig. 11: RC circuit

Bibliography

1. J. H. Arthur and M. R. Sexton, "LabVIEW application: energy laboratory upgrade," Proceedings of the 2002 ASEE Annual Conference an Exposition, Session 3233, CD-ROM, 2002.

2. I. I. Orabi, "Application of LabVIEW for undergraduate lab experiments on materials testing," Proceedings of the 2002 ASEE Annual Conference an Exposition, Session 2168, CD-ROM, 2002.

3. R. Bachnak and C. Steidley, "An interdisciplinary laboratory for computer science and engineering technology," Journal of Computing in Small Colleges, Vol. 17, No. 5, 2002, pp. 186-192.

4. K. Resendez and R. Bachnak, "LabVIEW programming for internet-based measurements," Journal of Computing in Small Colleges, Vol. 18, No. 4, 2003, pp. 79-85.

5. J. Zhao, "Rejuvenate an old Tinius Olsen machine with computer data acquisition using its existing hardware and LabVIEW," Proceedings of the 2005 ASEE Annual Conference an Exposition, Session 1426, CD-ROM, 2005.

HOSNI I. ABU-MULAWEH

Hosni I. Abu-Mulaweh is Professor of Mechanical Engineering at Indiana University-Purdue University, Fort Wayne, Indiana. He earned his B.S., M.S., and Ph.D. in Mechanical Engineering from the University of MissouriRolla, Rolla, Missouri. His areas of interest are Heat Transfer, Thermodynamics, and Fluid Mechanics.

Proceedings of the 2007 American Society for Engineering Education Annual Conference \& Exposition Copyright $\odot$ 2007, American Society for Engineering Education 
Table 1: Sensor Locations and Nominal Values

\begin{tabular}{|c|c|c|c|}
\hline Position & Air/Refrigerant & Measurement & Controlled \\
\hline 5 & refrigerant & flow rate & No \\
\hline 8 & air & flow rate & $\mathrm{No}$ \\
\hline 1 & refrigerant & pressure & No \\
\hline 2 & refrigerant & pressure & No \\
\hline 3 & refrigerant & pressure & No \\
\hline 4 & refrigerant & pressure & No \\
\hline 5 & refrigerant & pressure & No \\
\hline 6 & refrigerant & pressure & No \\
\hline 7 & air & $\begin{array}{l}\text { relative } \\
\text { humidity }\end{array}$ & Yes \\
\hline 9 & air & $\begin{array}{l}\text { relative } \\
\text { humidity }\end{array}$ & No \\
\hline 7 & air & temperature & Yes \\
\hline 9 & air & temperature & No \\
\hline 1 & refrigerant & temperature & No \\
\hline 2 & refrigerant & temperature & $\mathrm{No}$ \\
\hline 3 & refrigerant & temperature & No \\
\hline 4 & refrigerant & temperature & No \\
\hline 5 & refrigerant & temperature & No \\
\hline 6 & refrigerant & temperature & No \\
\hline 8 & air & temperature & No \\
\hline
\end{tabular}

Table 2: Logic Conditions and Component Operation Cases

\begin{tabular}{|c|c|c|c|c|c|c|c|}
\hline & \multicolumn{2}{|c|}{ Sensor Conditions } & \multicolumn{5}{c|}{ Controlled Elements } \\
\hline Case & $\begin{array}{c}\text { Enclosure } \\
\text { Temperature } \\
\text { Condition }\end{array}$ & $\begin{array}{c}\text { Enclosure } \\
\text { Humidity } \\
\text { Condition }\end{array}$ & $\begin{array}{c}\text { Evaporator } \\
\text { Fan }\end{array}$ & $\begin{array}{c}\text { Condenser } \\
\text { Fan }\end{array}$ & $\begin{array}{c}\text { Bubbler } \\
\text { Air } \\
\text { Pump }\end{array}$ & $\begin{array}{c}\text { Stream } \\
\text { Heating } \\
\text { Element }\end{array}$ & Compressor \\
\hline 1 & + & + & 1 & 1 & 0 & 0 & 1 \\
\hline 2 & + & $@$ & 1 & 1 & 0 & 1 & 1 \\
\hline 3 & + & - & 1 & 1 & 1 & 0 & 1 \\
\hline 4 & - & + & 1 & 1 & 0 & 1 & 1 \\
\hline 5 & - & $@$ & 1 & 0 & 0 & 1 & 0 \\
\hline 6 & - & - & 1 & 0 & 1 & 1 & 0 \\
\hline 7 & $@$ & + & 1 & 1 & 0 & 1 & 1 \\
\hline 8 & $@$ & $@$ & 0 & 0 & 0 & 0 & 0 \\
\hline 0 & $@$ & - & 1 & 0 & 1 & 0 & 0 \\
\hline
\end{tabular}

